\title{
Compatibilização de um projeto arquitetônico e hidrossanitário utilizando a metodologia BIM
}

\author{
Compatibilization of an architectural and hydrossanitary project using the BIM methodology \\ Compatibilización de un proyecto arquitectónico e hidrosanitario utilizando la metodología BIM
}

Recebido: 12/02/2021 | Revisado: 20/02/2021 | Aceito: 22/02/2021 | Publicado: 28/02/2021

\author{
André Borges Coutinho \\ ORCID: https://orcid.org/0000-0002-1864-3405 \\ Universidade Federal de São João del-Rei, Brasil \\ E-mail: andrecoutinho98@hotmail.com \\ Guilherme Souza Moura \\ ORCID: https://orcid.org/0000-0002-8156-4988 \\ Universidade Federal de São João del-Rei, Brasil \\ E-mail: guilhersm@gmail.com \\ Emmanuel Kennedy Costa Teixeira \\ ORCID: https://orcid.org/0000-0001-7598-0240 \\ Universidade Federal de São João del-Rei, Brasil \\ E-mail: emmanuel.teixeira@ufsj.edu.br
}

\begin{abstract}
Resumo
A presença de incompatibilidades em projetos hidrossanitários é frequente nos projetos tradicionais em $2 \mathrm{D}$. Com a evolução do mercado de construção civil e a demanda por projetos otimizados, os métodos de trabalhos precisam se manter atualizados. Deste modo, uma forma de integrar os profissionais envolvidos no ciclo de vida da construção ocorre pelo Building Information Modelling (BIM). Ele permite a visualização da edificação antes de ser construída, possibilitando a verificação de interferências e promovendo soluções eficientes. Entretanto, o BIM ainda não foi efetivamente implementado no Brasil, havendo muitas empresas na fase inicial de sua adoção e poucos estudos práticos a respeito da metodologia na área de projetos hidrossanitários. Logo, o objetivo deste trabalho foi verificar a aplicabilidade da metodologia BIM na modelagem 3D de um projeto hidrossanitário. Para isso, reproduziu-se o projeto arquitetônico juntamente ao de água fria e esgoto em ambiente BIM, buscando incompatibilidades. Após solucioná-las, geraram-se cortes, vistas e tabelas quantitativas, das quais se fez uma análise da automatização e dos impactos gerados pelos conflitos. Finalizado o estudo, observou-se a eficiência do BIM no que se refere à automatização para elaboração de projetos interdisciplinares, além de oferecer maior dinamismo ao planejamento da obra e reduzir retrabalho.
\end{abstract}

Palavras-chave: Modelagem; Automatização; Incompatibilidades.

\begin{abstract}
The presence of incompatibilities in hydrosanitary projects is frequent in the traditional 2D project. With the evolution of the civil construction market and a demand for optimized projects, work methods need to stay updated. Therefore, a way to integrate the professionals involved in the construction life cycle is through the Building Information Modeling (BIM). It allows the visualization of the building before construction, permitting an interference check and promoting efficient solutions. However, BIM hasn't been implemented in Brazil yet, having many companies in the initial phase of its adoption and few practical studies about the methodology in the area of cold water and sewer projects. So, the objective of this paper was to verify the applicability of the BIM methodology in 3D modeling of a hydrosanitary project. Thus, the architectural project was reproduced with the cold water and sewer project in Revit, seeking incompatibilities. After solving them, sections, views and quantities were generated, from which an analysis of automation and the impacts caused by conflicts was made. At the end of the study, BIM's efficiency with regard to automation for doing interdisciplinary projects was observed, in addition to offering better dynamism to the planning of the work and reducing rework.
\end{abstract}

Keywords: Modeling; Automation; Incompatibilities.

\section{Resumen}

La presencia de incompatibilidades en proyectos hidrosanitarios es frecuente en el proyecto $2 \mathrm{D}$ tradicional. Con la evolución del mercado de la construcción civil y la demanda de proyectos optimizados, los métodos de trabajo deben mantenerse actualizados. Por tanto, una forma de integrar a los profesionales implicados en el ciclo de vida de la construcción es a través del Building Information Modeling (BIM). Permite la visualización del edificio antes de la construcción, permitiendo un control de interferencias y promoviendo soluciones eficientes. Sin embargo, BIM aún no 
se ha implementado en Brasil, habiendo muchas empresas en la fase inicial de su adopción y pocos estudios prácticos sobre la metodología en el área de proyectos de agua fría y alcantarillado. Entonces, el objetivo de este trabajo fue verificar la aplicabilidad de la metodología BIM en el modelado 3D de un proyecto hidrosanitario. Así, el proyecto arquitectónico se reprodujo con el proyecto de agua fría y alcantarillado en Revit, buscando incompatibilidades. Después de resolverlos, se generaron secciones, vistas y cantidades, a partir de las cuales se realizó un análisis de la automatización y los impactos provocados por los conflictos. Al final del estudio se observó la eficiencia de BIM en cuanto a la automatización para la realización de proyectos interdisciplinares, además de ofrecer un mejor dinamismo a la planificación de la obra y reducir el retrabajo.

Palabras clave: Modelado; Automatización; Incompatibilidades.

\section{Introdução}

Os projetos básico e executivo são de suma importância para a execução de uma obra, podendo inviabilizar a construção por inconsistências quantitativas e qualitativas, como apontado por Lachi (2016). Seu processo de elaboração está em constante evolução, o que antes era feito a mão com tinta e gabaritos em um papel vegetal, passou a ser representado em softwares $2 \mathrm{D}$ e hoje é reproduzido em 3D. Esta reprodução pode ser realizada de maneira automatizada e promovendo a comunicação entre todos profissionais envolvidos no projeto, por meio do Building Information Modelling (BIM), traduzido para o português como modelagem da informação da construção. O BIM se trata de uma metodologia que integra arquitetos, engenheiros e construtores (AEC) ao gerenciamento digital do projeto e seus dados ao longo da construção (Eastman et al., 2008). Ele permite a visualização do empreendimento em um mundo virtual antes da sua execução, utilizando elementos inteligentes, onde cada material inserido no modelo possui um análogo no mundo real (Crotty, 2012).

A integração tanto das fases de concepção e execução do projeto, como dos inúmeros profissionais que participam dele por meio de diferentes softwares, resultam na interoperabilidade, a qual exige um trabalho colaborativo (Dias et al., 2015). Essa relação se estabelece pela troca de dados entre os softwares, podendo evitar incompatibilidades e otimizar o fluxo das informações. Para que ocorra a interoperabilidade, adota-se como um dos protocolos padrões o Industry Foudation Classes (IFC), o qual é um modelo de dados capaz de proporcionar a integração entre as diferentes modalidades de projetos (Rodrigues et al., 2017).

Com a utilização do BIM, todo o processo é parametrizado e deste modo se obtém um modelo em 3D que engloba toda a vida útil da edificação. Neste modelo, o projetista controla os parâmetros de todos os materiais utilizados, como altura de portas, espessuras de paredes, dimensões do piso, diâmetro e rugosidade de tubulações e perda de carga. Tais informações são associadas ao modelo, que ao serem alteradas, são atualizadas automaticamente em todos os componentes vinculados. Além do modelo 3D gerado em uma das plataformas BIM, é possível alcançar outros níveis de desenvolvimento, como planejamento, orçamento e gestão de instalações por meio do Integrated Project Delivery (IPD), traduzido para o português como entrega integrada de projetos, que caracteriza o último estágio de implantação do BIM, conforme Succar (2008).

No Brasil, pelos dados da Sienge e Grant Thornton (2020), 61,59\% das empresas ainda não utilizam a metodologia BIM. Uma das formas para aumentar a adesão do BIM é a implementação do Decreto $\mathrm{N}^{\circ} 10.306$, de 2 de abril de 2020 (Brasil), que prevê a implantação de uma estratégia denominada BIM BR, onde haverá investimentos em marketing e difusão do tema com o escopo de aumentar a produtividade e adoção do BIM, reduzir custos e elevar o PIB da construção civil (BIM BR, 2018). Já existem algumas instituições públicas que possuem grupos de pesquisas voltados para o desenvolvimento da metodologia, a exemplo da USP, UNICAMP, UFRGS e UFV (Kassem \& Amorim, 2015). Contudo, apesar dos investimentos, as empresas devem estar preparadas para sua implementação, uma vez que a adoção do BIM não se trata apenas da aplicação de uma tecnologia, e sim de uma nova metodologia de trabalho. Segundo Lima et al. (2016), o BIM se trata de um agente modificador do processo de projeto e gestão das informações, sendo que seu uso superficial limita a extração de todos benefícios oferecidos (Carmona \& Carvalho, 2017).

Na cidade de Belo Horizonte, Stehling e Arantes (2014) realizaram uma pesquisa com profissionais de AEC, 
constatando que a implantação do BIM em empresas de projetos arquitetônicos se encontra na etapa de transição entre o modelo 2D tradicional e o modelo 3D parametrizado, o que prejudica o processo de interoperabilidade dos projetos, uma vez que não se extrai todo o potencial da metodologia. Salomão et al. (2019) fizeram um estudo analisando a aplicação do BIM para uma edificação do programa Minha Casa Minha Vida, concluindo que ele possui grande relevância na compatibilização dos projetos, reduzindo gastos e retrabalho. N. Li et al. (2018) notaram, através de estudos na China, que a utilização do BIM reduz desperdício de material e tempo de construção.

Ocorre que, apesar do potencial e dos benefícios citados, ainda existem poucos artigos publicados, na área de projetos de água fria e esgoto, que evidenciam as vantagens da aplicação da metodologia BIM, sendo eles normatizados pelas NBR 5626 e NBR 8160. Salienta-se que os projetos hidrossanitários devem estar integrados de forma harmônica com o projeto arquitetônico, promovendo uma fácil operação das instalações e simplificando o processo de manutenção (Carvalho, 2018). No Brasil, um dos trabalhos que tratou da aplicação da metodologia BIM ao projeto hidrossanitário foi o realizado por Lima et al. (2016), através de pesquisas e entrevistas envolvendo empresas de pequeno, médio e grande porte do segmento AEC. Os autores detectaram que o mau planejamento durante as fases da concepção de um projeto hidrossanitário aumenta a ocorrência de incompatibilidades e resulta em desperdício de recursos. Entretanto, não verificaram a aplicabilidade do BIM na modelagem de um projeto hidrossanitário. Desta forma, tendo em vista a escassez de pesquisas práticas sobre o tema, o presente trabalho envolveu a compatibilização do projeto arquitetônico com o hidrossanitário de água fria e esgoto.

Assim, o objetivo deste trabalho foi aplicar a metodologia BIM na modelagem em 3D do projeto arquitetônico e hidrossanitário, previamente modelados no formato tradicional 2D. Desta forma, solucionaram-se as incompatibilidades existentes do projeto original, as quais foram identificadas com auxílio da visualização 3D. O estudo resultou em um projeto interdisciplinar compatibilizado com detalhamento realista e automatizado da edificação, onde se fez uma análise das tabelas quantitativas antes e depois de solucionar os conflitos, verificando os recursos desperdiçados e evitando imprevistos durante a execução da obra.

\section{Metodologia}

Para avaliar o uso da metodologia BIM, fez-se o estudo de caso utilizando o método qualitativo, conforme descrito em Pereira et al. (2018). Para isso, no software Revit, fez-se a integração do projeto arquitetônico executivo aos projetos complementares de água fria e esgoto de uma residência unifamiliar. Ela possui 626,22 m², um pavimento térreo, composta por três suítes, um closet, três banheiros sociais, escritório, depósito, despensa, cozinha, área de serviço, quarto de hóspedes, espaço gourmet, sala de estar com jantar, garagem com quatro vagas, jardim e piscina. Após a análise e entendimento completo da edificação, a partir dos projetos originais em 2D, fez-se a modelagem 3D, obtendo seus devidos cortes e dados quantitativos. Por conseguinte, investigaram-se as incompatibilidades e criou-se um novo projeto hidrossanitário compatibilizado, do qual foram retiradas as tabelas quantitativas a fim de compará-las ao modelo inicial.

\subsection{Modelagem dos projetos arquitetônico e hidrossanitário}

Para a realização da modelagem, primeiramente construiu-se um template no Revit para o projeto arquitetônico, com as especificações das paredes, famílias de portas, janelas e demais elementos parametrizados. A modelagem foi iniciada com a inserção de paredes e pisos, seguida de esquadrias e demais componentes do layout de cada ambiente. Finalizando o interior da residência, implantou-se o abrigo da caixa d'água, cobertura, jardim e piscina. Por fim, detalhou-se o gradil e a fachada principal com vidros, portões, cobogó e seus devidos revestimentos. Feito isso, a planta baixa foi gerada automaticamente, onde se delimitaram os ambientes e especificaram-se as áreas, níveis, cotas e demais legendas do projeto.

Ao fim da modelagem arquitetônica, fez-se o estudo do projeto hidrossanitário original, o qual já foi obtido pronto, 
sendo que o projetista utilizou um software 2D para apresentá-lo. Para a modelagem no Revit, levou-se em conta o traçado das tubulações e utilizou-se um template já pronto. De posse do template para projetos hidrossanitários, criou-se um arquivo no Revit vinculado ao projeto arquitetônico. Sendo assim, foram traçadas as tubulações, conexões, chuveiros, torneiras, vasos sanitários e caixas d'água conforme o projeto original. Em seguida, fez-se a modelagem do projeto de esgoto, no qual foram instaladas as conexões, tubulações, caixas de inspeção e gordura com seus devidos prolongadores, sifões e ralos, seguindo também o projeto original.

\subsection{Incompatibilidades existentes entre os projetos}

Finalizados os traçados originais, iniciou-se a busca por conflitos ao longo dos projetos, partindo da análise individual do projeto arquitetônico, em que as medidas do projeto, as áreas e níveis dos ambientes e sobreposição das paredes foram conferidos. Em seguida, com o modelo 3D do projeto hidrossanitário original integrado ao projeto arquitetônico, fez-se uma investigação com intuito de encontrar possíveis conflitos existentes, observando o caminhamento das tubulações de água fria e esgoto, conexões e dispositivos hidráulicos.

Ao término desta averiguação, criou-se um novo arquivo, também vinculado ao projeto arquitetônico, a fim de solucionar as incompatibilidades do projeto hidrossanitário, obter um projeto mais adequado para execução e verificar o impacto do uso de ferramentas BIM para a compatibilização de projetos.

\subsection{Automatização de cortes, vistas e quantitativos}

Por fim, também no Revit, buscou-se analisar a automatização alcançada a partir do BIM. Para isso, foram gerados cortes, plantas, fachadas, vistas e quantitativos. Neles, ponderou-se o grau de detalhamento e a praticidade, visto que qualquer alteração realizada no modelo 3D é atualizada simultaneamente nos elementos citados previamente neste tópico. Com as tabelas quantitativas elaboradas, fez-se uma comparação entre o comprimento total das tubulações antes e após a resolução de incompatibilidades, com o intuito de mostrar o que os conflitos entre os projetos podem ocasionar na execução da obra.

\section{Resultados e Discussão}

\subsection{Modelagem dos projetos arquitetônico e hidrossanitário}

Realizada a modelagem, obtiveram-se os projetos e as tabelas referentes aos quantitativos da construção, elaborados no Revit. A Figura 1 representa a renderização, feita no próprio software, do projeto arquitetônico concluído, com os layouts, pisos, paredes, ambientes e texturas devidamente configurados. A partir do modelo arquitetônico, criou-se um vínculo no qual se integrou o projeto hidrossanitário compatibilizado de água fria e esgoto, representado pela Figura 2. Nela se exibe todo o sistema de água fria, desde a alimentação da caixa d'água até o abastecimento dos cômodos, assim como o sistema de esgoto, englobando as tubulações, conexões, caixas sifonadas, caixas de inspeção e caixas de gordura. 
Figura 1 - Resultado final do projeto arquitetônico (3D).

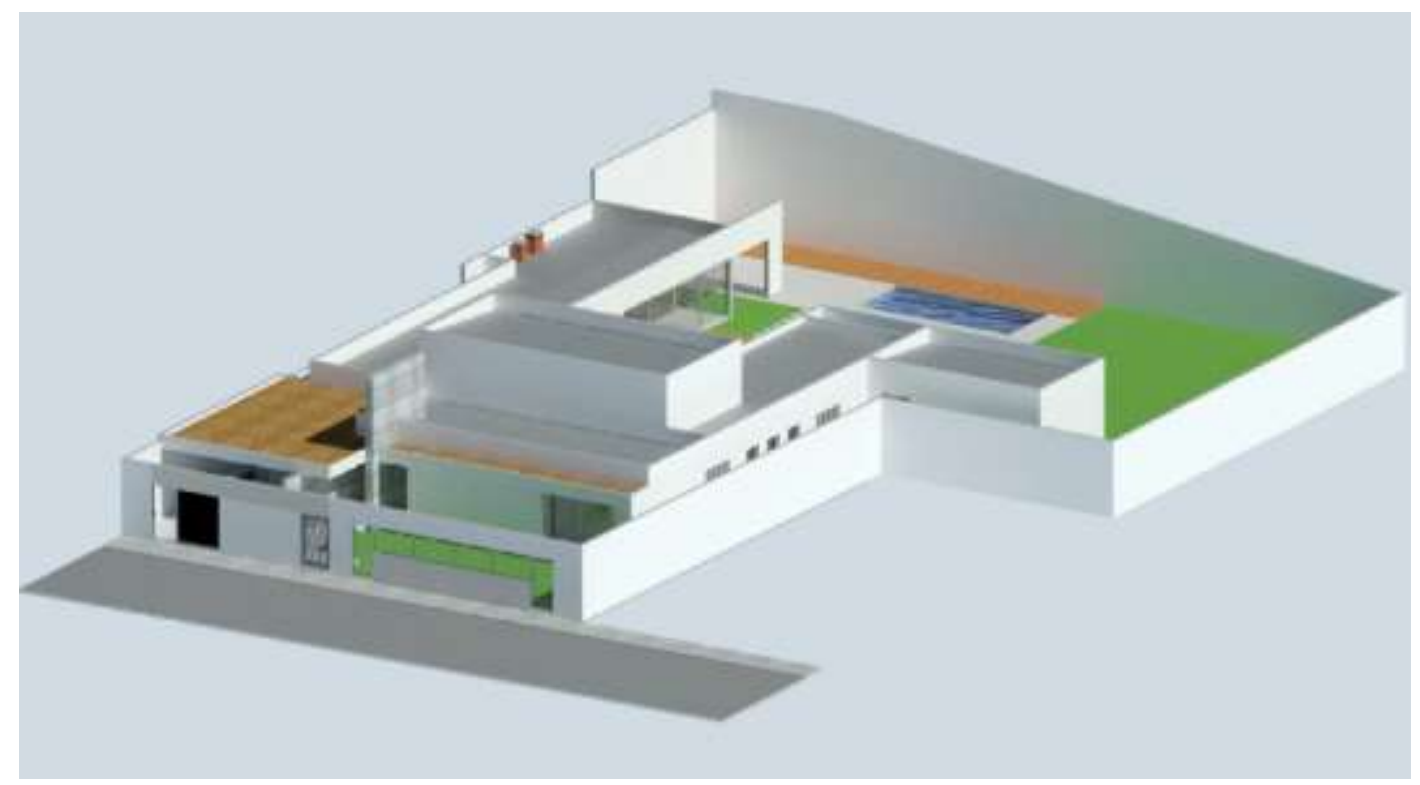

Fonte: Autores (2020).

Figura 2 - Resultado final do projeto hidrossanitário compatibilizado (3D).

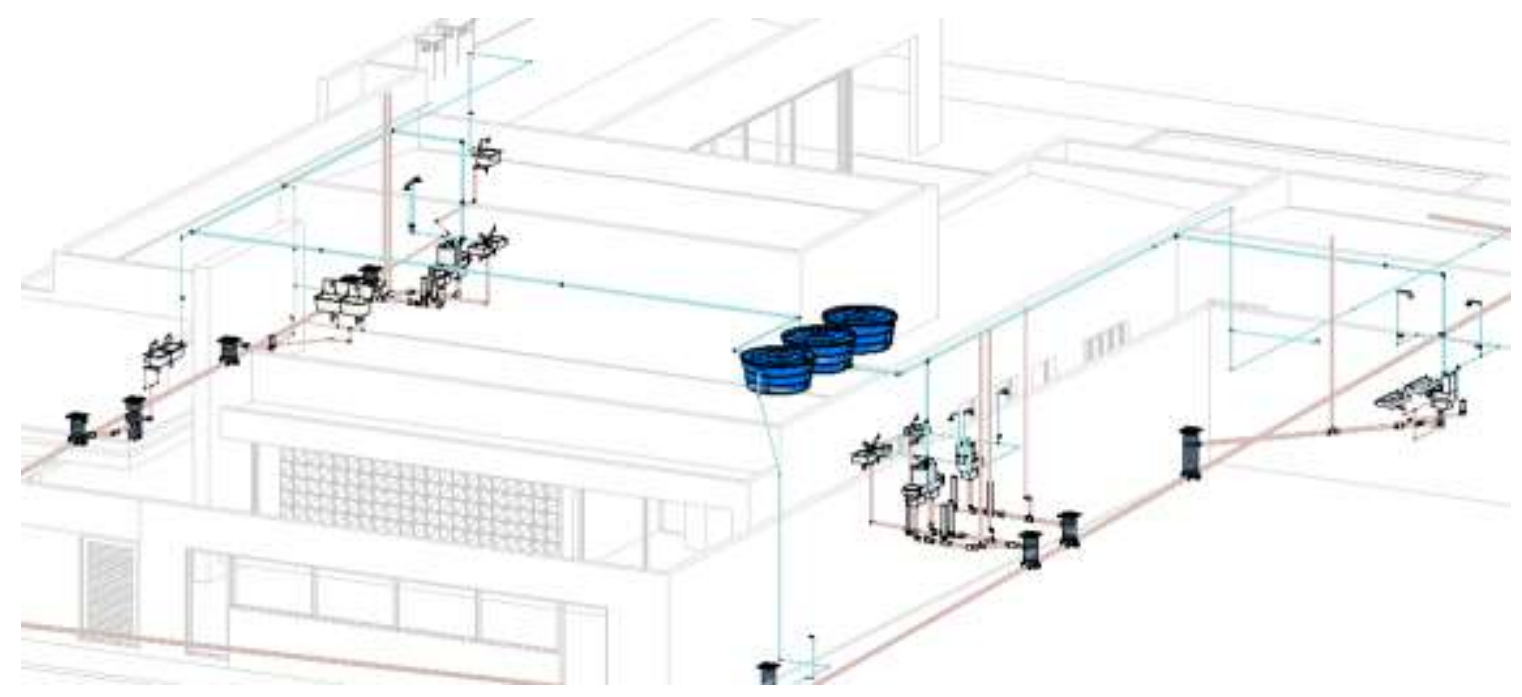

Fonte: Autores (2020).

Ao fim da modelagem, notou-se um projeto mais realista e claro devido à visualização 3D, além de possuir mais informações em cada elemento, como, por exemplo, a porta, onde se configurou desde o material da folha até a maçaneta. Destaca-se que de todo o processo de modelagem em um software BIM, a maior parte do tempo foi gasta na fase inicial, em que se configuraram os objetos parametrizados. Porém, ao fim desta configuração, notou-se que as alterações no modelo foram feitas de maneira eficiente, despendendo menos esforço por parte do projetista, como evidenciado pela curva de Macleamy, exposta no trabalho de Prušková (2018). Esta curva apresenta que, com a utilização do BIM, o fluxo de trabalho é mais intenso na fase de detalhamento do projeto pré-executivo, em que ocorrem as configurações dos materiais e a modelagem é iniciada. Já no processo tradicional de trabalho, há mais esforço na fase de projeto executivo e documentação, devido ao tempo demandado para as correções de projeto, que devem ser feitas manualmente devido a não automatização entre plantas, cortes e tabelas quantitativas. 


\subsection{Incompatibilidades existentes entre os projetos}

Num processo habitual, após a elaboração dos projetos, a análise e revisão é feita em um arquivo 2D, geralmente por profissionais diferentes, sem nenhum vínculo entre eles, o que pode gerar perda de informações (Basto \& Lordsleem, 2016). Portanto, antes de começar a modelagem, realizou-se uma análise dos projetos originais executados no AutoCAD. Em uma segunda etapa, após a modelagem feita no Revit, iniciou-se um processo de buscas por conflitos entre os projetos.

Observou-se que, apesar do projeto ser de um núcleo unifamiliar, com um pavimento, sendo ele térreo, houve treze inconformidades e com impacto visível na residência, as quais estão representadas na Figura 3. Sendo assim, o BIM contribuiu para que estas interferências fossem constatadas antes da execução da obra, identificando problemas já na fase de projeto, como também observado por Rodrigues et al. (2017).

Após a análise dos conflitos entre os projetos foram propostas soluções, a fim de viabilizá-los. A Figura 4a apresenta a incompatibilidade de número 5 da Figura 3, envolvendo o projeto de água fria e o arquitetônico. Nela, observa-se uma tubulação que ficou aparente no jardim da residência, destacada em vermelho (Figura 4a). A solução para este problema está apresentada na Figura 4b, em que se traçou um novo caminhamento para a tubulação, passando por dentro da residência. Desta forma, criou-se uma parede hidráulica responsável por abastecer a cozinha, área de serviço, banheiros e espaço gourmet.

Figura 3 - Incompatibilidades encontradas na edificação.

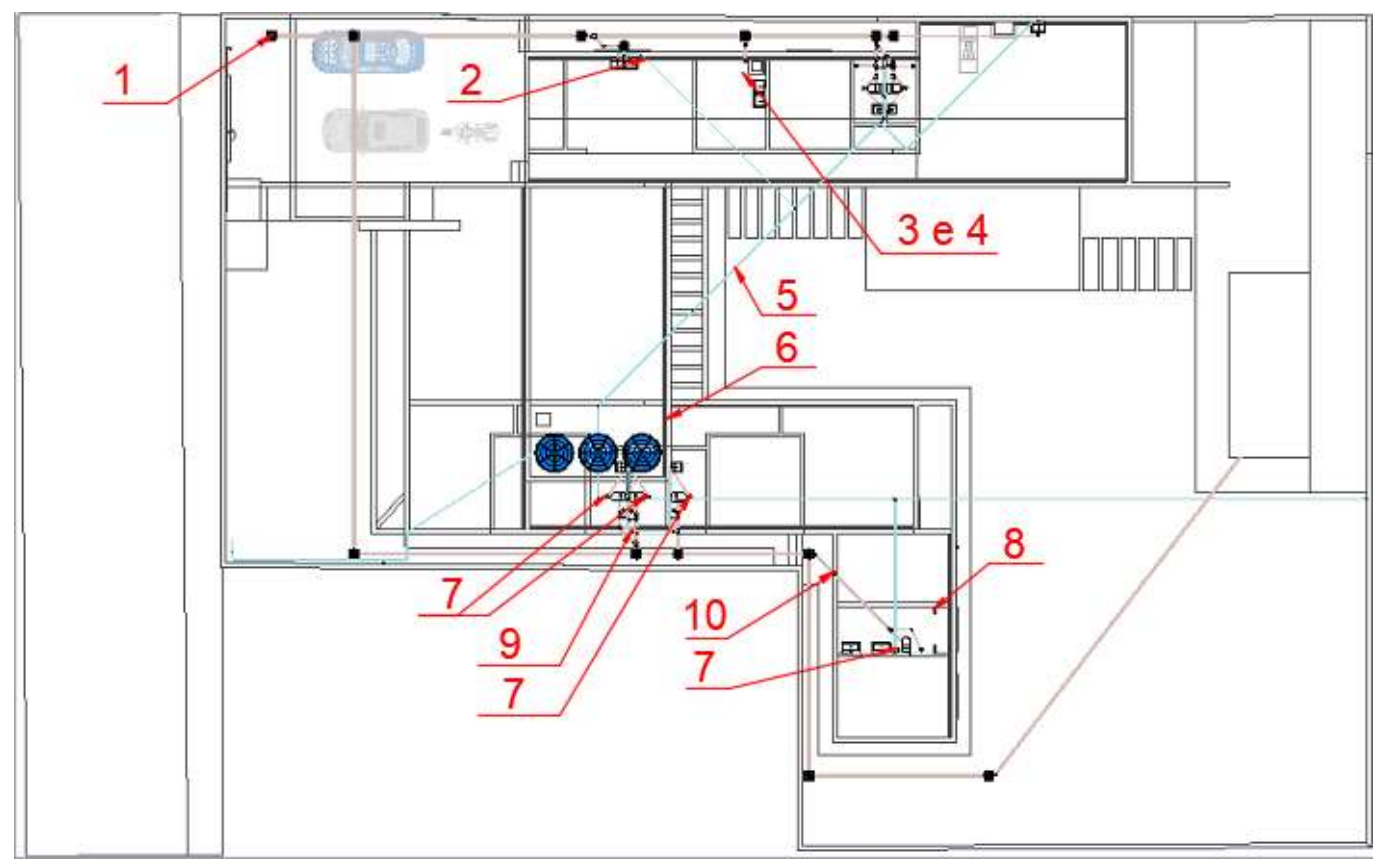

Fonte: Autores (2020). 
Research, Society and Development, v. 10, n. 2, e58610212924, 2021

(CC BY 4.0) | ISSN 2525-3409 | DOI: http://dx.doi.org/10.33448/rsd-v10i2.12924

Figura 4 - (a) Incompatibilidade e (b) solução para o problema de tubulação aparente no jardim.

(a)

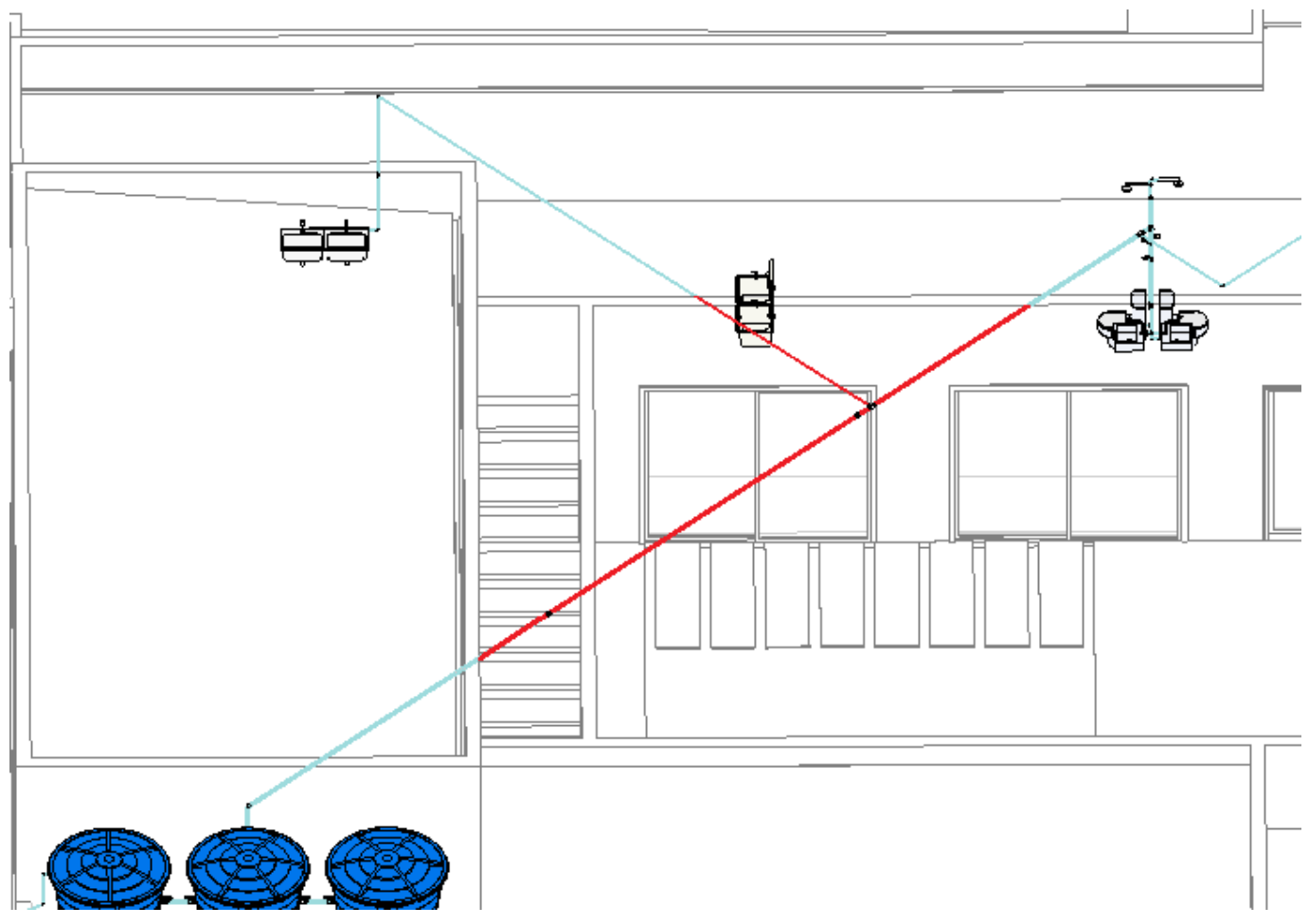

(b)

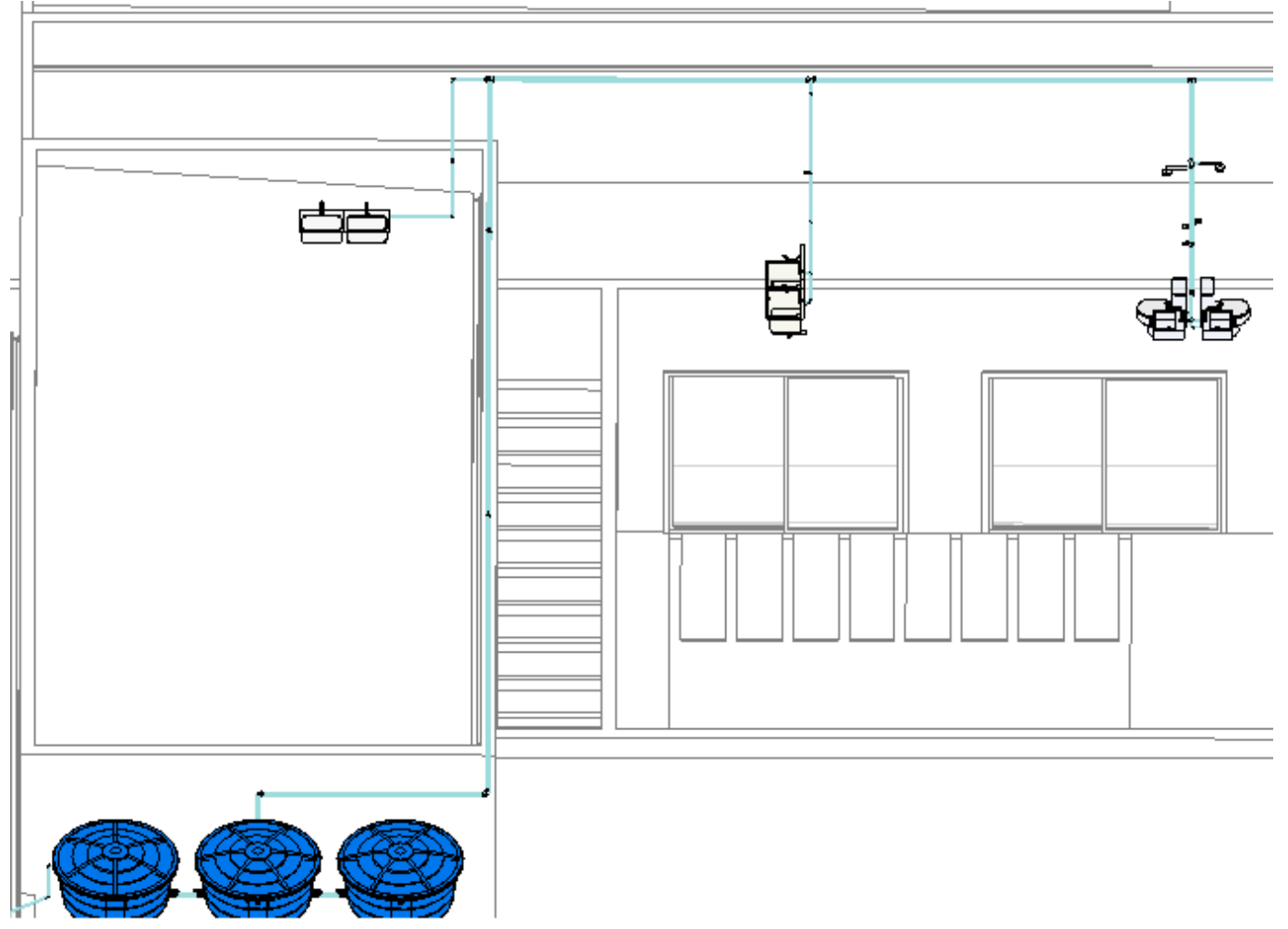

Fonte: Autores (2020).

Na Figura 4a, observa-se a ineficiência de um projeto 2D no quesito de compatibilização, visto que em uma planta são consideradas apenas duas dimensões, sendo elas largura e comprimento (eixo x e y), já a altura (eixo z) só é representada em um projeto 3D. O Revit possibilitou a visualização 3D, a partir da qual foi possível propor um novo traçado para a tubulação de água fria, evitando que ela ficasse aparente sobre o jardim. Tal conflito se deu devido a sobreposição de plantas em 2D ser um processo de compatibilização restrito, sobretudo em projetos hidrossanitários e elétricos, os quais contêm uma grande 
quantidade de informações, conforme apontado por Salomão et al. (2019).

Outro conflito entre projetos foi o cruzamento da tubulação de água fria com a tubulação de ventilação de um dos banheiros, representado pelo número 9 da Figura 3. Esta incompatibilidade é apresentada também na Figura 5a e a sua solução baseou-se no deslocamento do sistema de ventilação, mantendo-o dentro da alvenaria, porém sem estar em contato com a tubulação de água fria, indicado na Figura 5 b.

Assim, como este caso foi analisado a partir de um projeto 3D, a visualização foi facilitada. Além disso, só foi possível verificá-lo devido à interação entre os projetos de água fria e esgoto. Por conseguinte, utilizando-se a metodologia BIM, percebe-se que as incompatibilidades são identificadas em uma etapa anterior à execução da obra, o que tende a reduzir os imprevistos de canteiro, ajustando cronogramas e otimizando a visualização dos modelos, como também observado por Motamedi et al. (2017).

Figura 5 - (a) Incompatibilidade e (b) solução entre o projeto de água fria e esgoto.

(a)

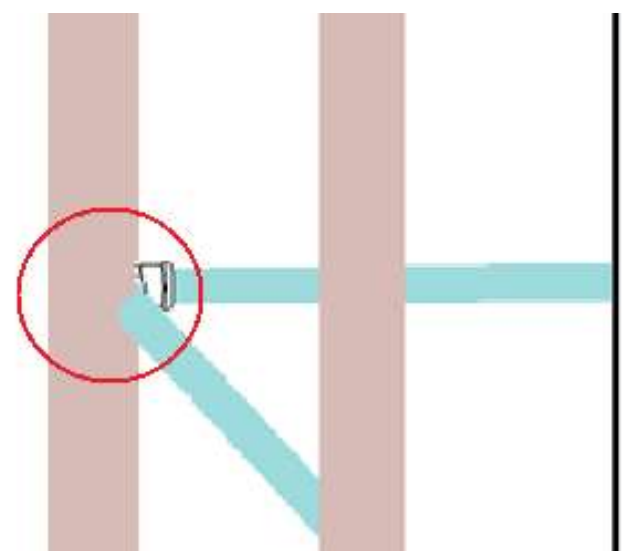

(b)

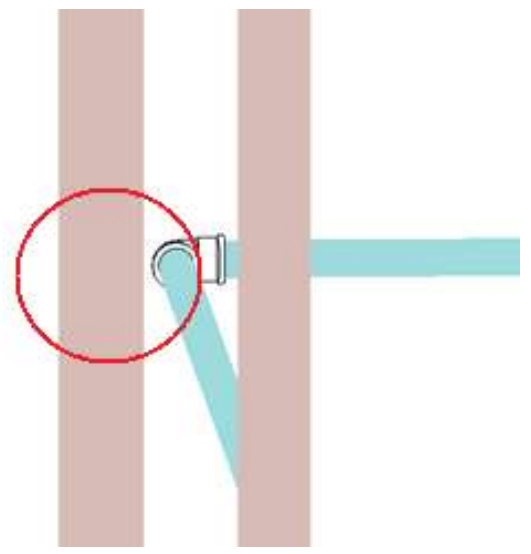

Fonte: Autores (2020).

No projeto hidrossanitário original, verificaram-se em duas situações o conflito entre janelas e tubulações. Em um dos casos (número 10 da Figura 3) a tubulação de ventilação cruzou a janela do closet, o qual foi solucionado ao deslocar o tubo para a parede que separa o closet do banho do casal. Já no outro caso representado pela Figura 6a, número 2 da Figura 3, a tubulação de água fria que alimenta a cozinha atravessou a janela posicionada atrás da pia, destacada em vermelho. Para resolver esta incompatibilidade, mudou-se a localização do tubo e do registro para a direita da janela, conforme Figura 6 b.

Além das incompatibilidades detalhadas, houve outras nove também representadas na Figura 3, sendo o conflito de número 1 referente à profundidade da caixa de inspeção responsável pela ligação do ramal interno da residência à rede coletora, uma vez que a profundidade alcançada foi de $2,03 \mathrm{~m}$. O recomendado na região é de $0,70 \mathrm{~m}$ a 1,0 m. Como o objetivo do estudo não foi alterar o dimensionamento, optou-se por não modificar as inclinações definidas pelo projetista. Desta forma, a partir das adaptações no caminhamento do projeto, a nova profundidade foi de 1,65 m, salientando que caso as inclinações fossem reduzidas, a altura do ramal estaria mais adequada. 
Figura 6 - (a) Incompatibilidade e (b) solução para a tubulação aparente na cozinha.

(a)

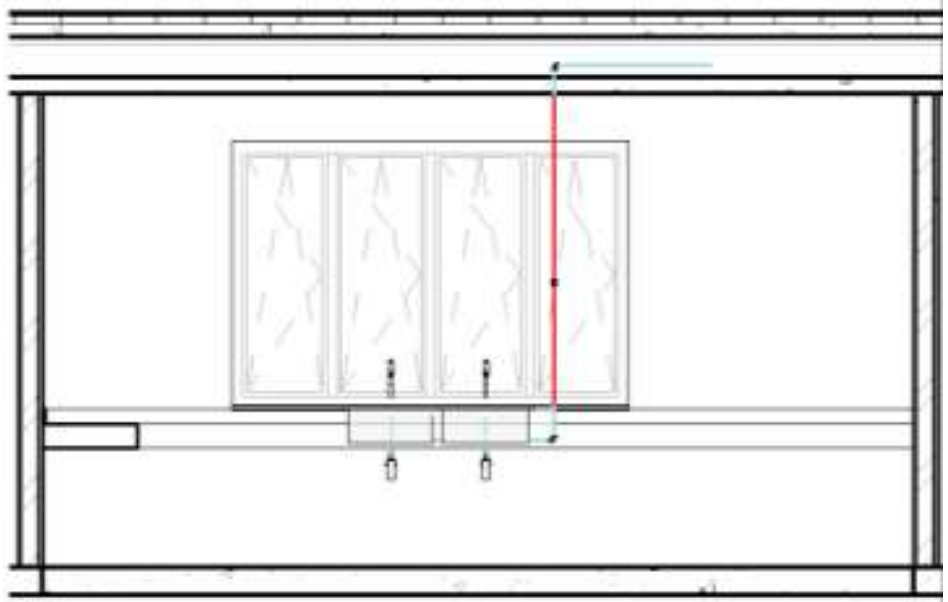

(b)

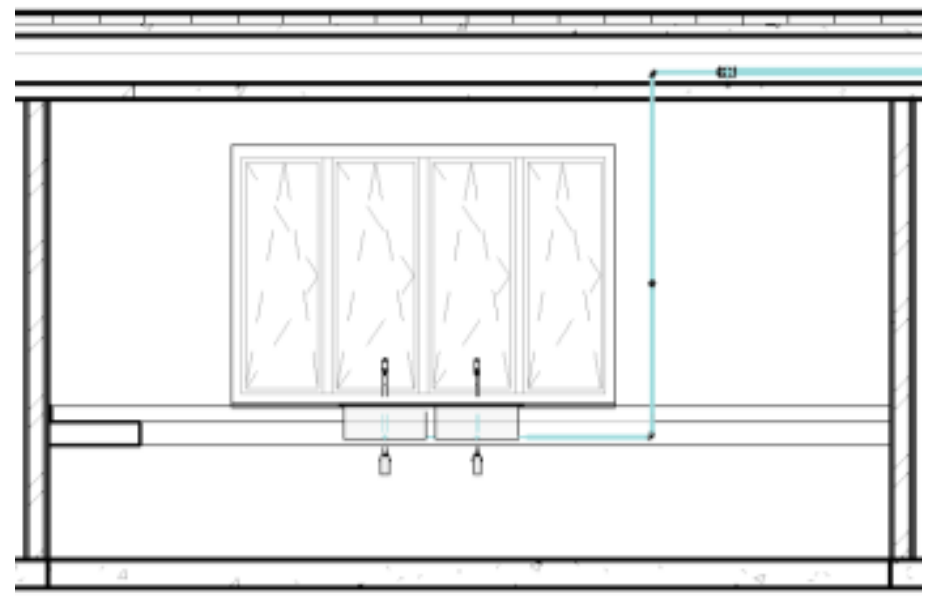

Fonte: Autores (2020).

Os conflitos de número 3 e 4 (Figura 3) denotam que em todo projeto hidrossanitário original de água fria e esgoto não se levou em consideração a área de serviço. A incompatibilidade de número 8 representa um dos chuveiros do banho do casal, o qual não foi incorporado no projeto de água fria. Já as incompatibilidades de número 7 indicam que, em quatro banheiros da residência, as caixas sifonadas não foram ligadas ao sistema de esgoto.

No projeto compatibilizado, o traçado das ligações foi feito adequando a área de serviço ao sistema hidrossanitário, prolongando a alimentação que chega ao banheiro até o segundo chuveiro e conectando os ralos por meio de junções. É importante salientar que a falta da área de serviço e do chuveiro no sistema de água fria podem afetar diretamente o dimensionamento hidráulico, visto que, com novos trechos de tubulação, a perda de carga aumenta, podendo alterar o diâmetro adequado para a vazão demandada.

Por fim, a inconformidade de número 6 (Figura 3) se refere ao posicionamento do abrigo da caixa d'água, que divergiu entre as plantas do projeto arquitetônico. Tal divergência foi identificada ainda na fase de análise do projeto 2D, onde notou-se que a projeção do abrigo não condizia com as dimensões dele. Para sua correção, foi necessário o ajuste da posição do abrigo mantendo a área e alterando a projeção na construção. Ao executar a modelagem no Revit, a imprecisão relacionada a projeção de pavimentos superiores não ocorre, considerando que ao fazer o 3D a projeção é gerada automaticamente, não exigindo um esforço visual para compatibilização, por parte do projetista. Essa inconsistência afeta o leitor do projeto, seja ele o construtor, proprietário ou projetista, visto que os dados de uma planta não estavam condizentes com o de outra, dificultan do a interpretação. Esse ponto também foi observado por Brito e Ferreira (2015), visto que uma das maiores potencialidades do 
BIM está relacionada com a redução do esforço para interpretação mental, principalmente no planejamento de obras.

Durante a execução de obras, as incompatibilidades e os imprevistos surgem frequentemente. Neste estudo de caso, o BIM possibilitou virtualmente a visualização do processo de construção. Desta forma, as soluções foram encontradas de maneira antecipada, ao contrário do que ocorre no processo habitual, em que os problemas são detectados de maneira tardia e a decisão deve ser tomada rapidamente a fim de manter os prazos estabelecidos. Sendo assim, neste trabalho foi possível realizar a compatibilização entre o projeto arquitetônico e hidrossanitário, mostrando que o BIM se trata de um modelo inteligente e parametrizado de construção virtual 3D, que pode ser utilizado para desenvolver soluções otimizadas para construção, corroborando com o apresentado por Rodrigues et al. (2017).

\subsection{Automatização de cortes, vistas e quantitativos}

Após a modelagem do projeto arquitetônico, observou-se a eficiência do BIM no que se trata da automatização, dado que vistas, cortes, plantas e quantitativos são gerados automaticamente a partir do software Revit. A Figura 7 corresponde à fachada frontal da residência, em que se observou a praticidade em projetos arquitetônicos executivos, uma vez que terminada a modelagem, os traços de todos os cortes e vistas são obtidos de maneira direta, evitando retrabalho caso haja alterações no plano. Porém, uma ressalva que se faz é que as cotas, legendas e demais informações específicas do projeto devem ser configuradas manualmente pelo desenhista responsável.

Figura 7 - Fachada frontal da residência.

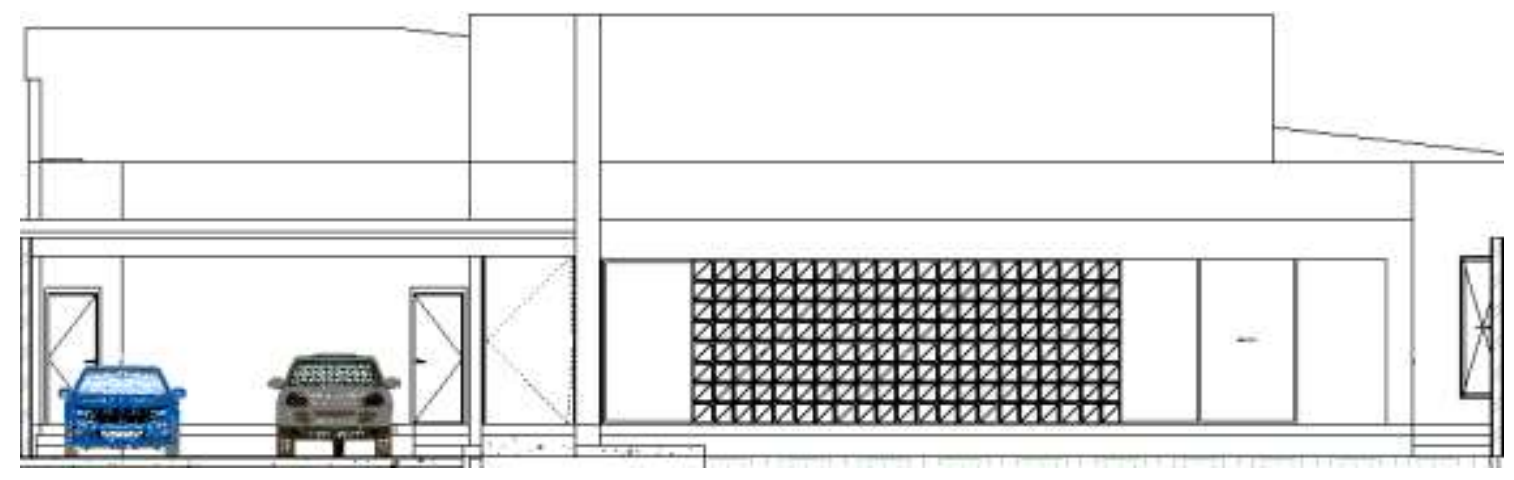

Fonte: Autores (2020).

A Figura 8 apresenta outro cenário em que a automatização torna a forma de projetar mais dinâmica. Nela está representada uma vista isométrica da suíte do casal, gerada a partir do modelo tridimensional do projeto hidrossanitário compatibilizado, em que as famílias das tubulações, conexões e peças hidrossanitárias estão integradas e parametrizadas.

Por meio da vista da Figura 8, nota-se que o resultado gráfico final gerado no Revit é semelhante ao obtido por ferramentas 2D. Contudo, observou-se que a maneira de se projetar utilizando ferramentas BIM foi diferente, visto que o cerne esteve nas soluções e integrações dos projetos, não se atendo apenas a representação visual por meio de linhas e sim a objetos "inteligentes", que possuem propriedades parametrizadas, como também apresentadas por Ruschel (2014). Entretanto, devido a implantação do BIM no Brasil ainda estar na fase inicial, notou-se que é necessária a otimização das famílias de projetos hidrossanitários, de forma a implementar mais objetos, como prolongadores para caixa de gordura, e melhorar a qualidade visual dos mesmos. 
Figura 8 - Vista isométrica da suíte do casal.

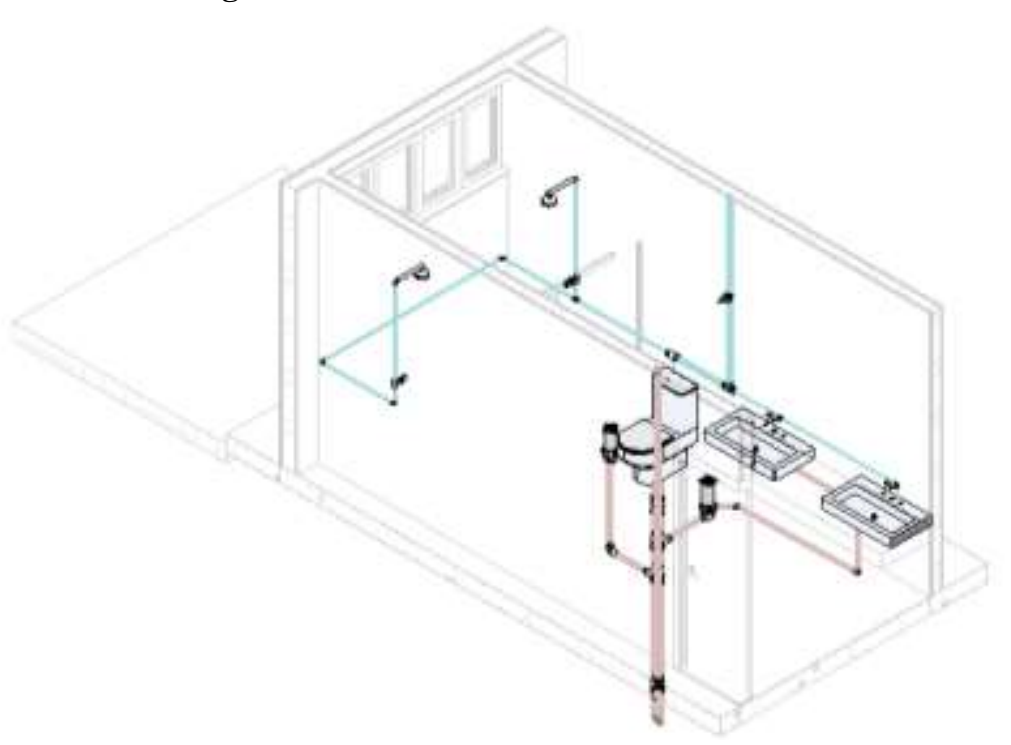

Fonte: Autores (2020).

Quando se utiliza um programa 2D, os quantitativos são levantados manualmente, exigindo uma análise minuciosa de cada elemento por parte do projetista, ocasionando imprecisões e, por conseguinte, erros na orçamentação. Já no 3D, o processo ocorreu de forma direta, em que o próprio software forneceu as tabelas, sendo que elas foram atualizadas de maneira integrada ao projeto. Assim, caso haja alterações no projeto, o quantitativo é atualizado automaticamente, evitando que ocorram falhas humanas no processo de elaboração das planilhas. Isto posto, utilizando-se desta automatização, fez-se uma análise comparativa das quantidades de tubo requeridas pelos projetos hidrossanitários antes e depois da compatibilização, representados na Tabela 1, com os quais será analisado o impacto na obra, como o apresentado por Rodrigues et al. (2017).

Tabela 1 - Quantitativo de tubulações do projeto original e compatibilizado.

\begin{tabular}{lccc}
\hline TIPO & $\begin{array}{c}\text { DIÂMETRO } \\
(\mathrm{mm})\end{array}$ & $\begin{array}{c}\text { COMPRIMENTO } \\
\text { ORIGINAL }(\mathrm{m})\end{array}$ & $\begin{array}{c}\text { COMPRIMENTO } \\
\text { ADAPTADO (m) }\end{array}$ \\
\hline PVC Água Fria - Tubo Soldável Tigre & 80,77 \\
PVC Água Fria - Tubo Soldável Tigre & 20 & 85,14 & 18,21 \\
PVC Água Fria - Tubo Soldável Tigre & 25 & 14,14 & 58,65 \\
PVC Água Fria - Tubo Soldável Tigre & 50 & 47,89 & 21,46 \\
& PVC Esgoto - Série Normal Tigre & 11,51 \\
PVC Esgoto - Série Normal Tigre & 40 & 16,06 & 0,14 \\
PVC Esgoto - Série Normal Tigre & 50 & 13,08 & 106,06 \\
PVC Esgoto - Série Normal Tigre & 75 & 0,14 & \\
PVC Esgoto - Série Normal Tigre & 100 & 117,97 & 28,07 \\
\hline
\end{tabular}

Fonte: Autores (2020).

Após a compatibilização do projeto hidrossanitário, devido aos conflitos encontrados, notou-se a divergência no 
comprimento total de cada diâmetro, sendo as mais elevadas nos tubos de esgoto de $100 \mathrm{~mm}$ (11,91 m, equivalente à redução de $10 \%)$, água fria de $50 \mathrm{~mm}(10,76 \mathrm{~m}$, equivalente a um acréscimo de 22,5\%) e ventilação de $50 \mathrm{~mm}(7,62 \mathrm{~m}$, equivalente a um acréscimo de 37,3\%). Logo, é evidente que um erro na fase de concepção deixa de ser um aspecto gráfico para ser um aspecto técnico capaz de prejudicar o andamento da obra. Desta forma, tem-se que a falta de compatibilização que ocorre no modelo de construção atual, a qual também foi observada por Leite et al. (2015), tende a provocar retrabalhos e o não cumprimento de prazos.

Este trabalho se tratou de uma edificação unifamiliar, com um pavimento, onde as incompatibilidades, embora existam, são de menor escala. Em obras de grande porte, os números de inconformidades tendem a serem maiores, gerando mais problemas. Assim, observou-se que, tendo como benefícios a automatização e a interação entre os projetos, o uso mais frequente da metodologia BIM possibilitará a redução da possibilidade de tais conflitos. Desta forma, tende-se a diminuir o retrabalho e os custos. Além disso, pode-se aumentar a produtividade e a precisão na compatibilização de projetos, como afirmado por Santos (2016).

\section{Conclusão}

Ao fim deste estudo, notou-se a eficiência da metodologia BIM na elaboração e compatibilização de projetos interdisciplinares, dado que concluída a modelagem do projeto arquitetônico e hidrossanitário, obteve-se uma visualização tridimensional integrada e realista que facilitou a interpretação do projeto e a identificação de incompatibilidades. Com isso, foi possível modelar um projeto hidrossanitário adaptado, onde foram reduzidas a presença de informações inconsistentes.

Além disso, a automatização para elaboração de cortes, vistas e plantas é vantajosa. Com o vínculo criado entre as partes componentes do projeto, as informações ficam contidas em um único modelo e as alterações, sejam elas por mudanças no plano ou incompatibilidades, são atualizadas em todo o projeto sem necessidade de retrabalho por parte do projetista. Ademais, as tabelas quantitativas são obtidas de maneira automática, dando dinamismo ao planejamento e orçamentação da obra e reduzindo o desperdício de materiais causados por erros de compatibilização de projeto.

O trabalho do BIM tende a concentrar mais energias nas etapas de detalhamento do projeto pré-executivo, a fim de reduzir problemas de conflitos durante as fases de construção e operação. Logo, a modelagem exige um nível de detalhamento superior ao de ferramentas 2D durante as fases preliminares de projeto, evidenciando que a forma de elaboração é modificada, despendendo mais tempo nas fases iniciais de desenvolvimento do projeto. Com isso, viu-se que apesar da mudança da filosofia de trabalho a utilização é positiva para o mercado de AEC, no que se trata da otimização de projetos e quantitativos.

Como sugestão para trabalhos futuros, recomenda-se a compatibilização dos demais projetos complementares para a edificação em estudo, como estrutural e elétrico, utilizando o Revit, de modo a procurar e solucionar as novas incompatibilidades. Somado a isso, realizar um estudo dos quantitativos a fim de encontrar um valor aproximado do prejuízo gerado pelos conflitos presentes.

\section{Referências}

ABNT NBR 5626, de 2020. Instalação predial de água fria. Associação Brasileira de Normas Técnicas.

ABNT NBR 8160, de 1999: Sistemas prediais de esgoto sanitário - Projeto e execução. Associação Brasileira de Normas Técnicas.

Basto, P. E. de A. \& Lordsleem Junior, A. C. (2016). Ensino de BIM em curso de graduação em engenharia civil em uma universidade dos EUA: estudo de caso. Ambiente Construído, 16(4), 45-61. http://dx.doi.org/10.1590/s1678-86212016000400104.

Brito, D. M. \& Ferreira, E. A. M. (2015). Avaliação de estratégias para representação e análise do planejamento e controle de obras utilizando modelos BIM 4D. Ambiente Construído, 15(4), 203-223. http://dx.doi.org/10.1590/s1678-86212015000400047.

Carmona, F. V. F. \& Carvalho, M. T. M. (2017). Caracterização da utilização do BIM no Distrito Federal. Ambiente construído, 17(4), 385-401. http://dx.doi.org/10.1590/s1678-86212017000400203. 
Carvalho Júnior, R. (2018). Instalações hidráulicas e o projeto de arquitetura (11a ed.). Blucher.

Crotty, R. (2012). The Impact of Building Information Modelling. SPON Press.

Dias, E. R. \& Arantes, E. M. (2015). Interoperabilidade de ferramentas de modelagem paramétrica em projetos de plantas industriais. Gestão e Tecnologia de Projetos, 10(2), 35-46. http://dx.doi.org.br/10.11606/gtp.v10i2.101369.

Eastman, C., Teicholz, P., Sacks \& R.; Liston, K. (2008). BIM Handbook: a guide to building information modeling for owners, managers, designers, engineers and contractors. John Wiley e Sons.

Kassem, M. \& Amorim, S. R. L. (2015). Building Information Modeling no Brasil e na União Europeia. Brasília: MDIC/EU. http://sectordialogues.org/sites/default/files/acoes/documentos/bim.pdf.

Lachi, D. K. M. (2016). Implantação da modelagem da informação da construção (Building Information Modeling) para elaboração de projetos básicos de obras e serviços de engenharia na UFGD (Dissertação de mestrado). Universidade Federal da Grande Dourados, Mato Grosso do Sul.

Leite, K. P., Neto, J. P. B., Teixeira, M. \& Claudino, C. (2015). Processo de projeto em empreendimentos imobiliários: avaliação de projetistas e construtores. Gestão e Tecnologia de Projetos, São Paulo, 10(2), 21-34. http://dx.doi.org/10.11606/gtp.v10i2.10205.

Li, N., Li, J., Peng, J., Cui, H. \& Wu, Z. (2018). A review of currently applied building information modeling tools of constructions in China. Elsevier, 201, 358-368. https://doi.org/10.1016/j.jclepro.2018.08.037.

Lima, C. F. M., Andery, P. R. P. \& Veiga, A. C. R. (2016). Análise do processo de projeto de sistemas hidrossanitários prediais. PARC Pesquisa em Arquitetura e Construção, 7(2), 102-113. http://doi.org/10.20396/parc.v7i2.8645049.

Ministério da Indústria, Comércio Exterior e Serviços, MDIC (2018). Estratégia BIM BR: Estratégia Nacional de Disseminação do Building Information Modelling - BIM. Brasília: MDIC. http://www.mdic.gov.br/images/REPOSITORIO/sdci/CGMO/Livreto_Estratgia_BIM_BR-6.pdf.

Motamedi, A., Wang, Z., Yabuki, N., Fukuda, T. \& Michikawa, T. (2017). Signage visibility analysis and optimization system using BIM-enabled virtual reality (VR) environments. Elsevier, 32, 248-262. https://doi.org/10.1016/j.aei.2017.03.005.

Pereira, A. S., Shitsuka, D. M., Parreira, F. J. \& Shitsuka, R. (2018). Metodologia da pesquisa científica. $1^{a}$ ed. Santa Maria, RS: UFSM Núcleo de Tecnologia Educacional. 119. 1. (119p.). https://repositorio.ufsm.br/bitstream/handle/1/15824/Lic_Computacao_Metodologia-Pesquisa-Cientifica.pdf?sequence=1.

Presidência da República. Decreto n. 10.306 de 2 de abril de 2020. Palácio do Planalto - Presidência da República. Brasília. 2020.

Prušková, K. (2018). Reducing failures rate within the project documentation using building Information Modelling, especially Level of Development. MATEC Web of Conferences, 146. https://doi.org/10.1051/matecconf/201814601009.

Rodrigues, K. C., Mesquita, H. C., Eduardo, R. C.; \& Paula, H. M. (2017). Mapeamento sistemático de referências do uso do BIM na compatibilização de projetos na construção civil. REEC, 13(1), 219-239. http://doi.org.br/10.5216/reec.V13i1.45014.

Ruschel, R. C. (2014). To Bim or Not To Bim? In III Encontro da Associação Nacional de Pesquisa e Pós-graduação em Arquitetura e Urbanismo Arquitetura, cidade e projeto: uma construção coletiva. ANPARQ.

Salomão, P. E. A., Costa, N. C., Gouvêa, D. L., Oliveira, A. N. S. \& Silva, A. J. M. (2019). Modelagem e compatibilização de projetos de uma residência Minha Casa Minha Vida em software de plataforma BIM. Research, Society and Development, 8(8). https://rsdjournal.org/index.php/rsd/article/view/1230.

Santos, R. S. (2016). Estudos de Caso de Implementação da Modelagem da Informação da Construção em Microescritórios de Arquitetura (Dissertação de mestrado). Instituto de Pesquisas Tecnológicas do Estado de São Paulo, São Paulo.

Sienge e Grant Thornton (2020). Mapeamento de maturidade BIM Brasil (p 15). Brasil: https://www.sienge.com.br/relatorio-mapeamento-de-maturidadebim/.

Stehling, M. P. \& Arantes, E. M. (2014). Análise do processo de implantação de BIM em empresas de projetos industriais e arquitetônicos em Belo Horizonte. PARC Pesquisa em Arquitetura e Construção, Campinas, 5(1), 35-44. http://doi.org/10.20396/parc.v7i2.8645049.

Succar, B. (2008). Building Information Modelling framework: a research and delivery foundation for industry stakeholders. Elsevier, 18(3), 357-375. http://doi.org/10.1016/j.autcon.2008.10.003. 